\title{
Effective indenter radius and frame compliance in instrumented indentation testing using a spherical indenter
}

\author{
Seung-Kyun Kang \\ Department of Materials Science and Engineering, Seoul National University, Seoul 151-744, Korea \\ Ju-Young Kim ${ }^{\text {a) }}$ \\ Materials Science, California Institute of Technology, Pasadena, California 91106 \\ Ingeun Kang and Dongil Kwon \\ Department of Materials Science and Engineering, Seoul National University, Seoul 151-744, Korea
}

(Received 31 January 2009; accepted 22 June 2009)

\begin{abstract}
We introduce a novel method to correct for imperfect indenter geometry and frame compliance in instrumented indentation testing with a spherical indenter. Effective radii were measured directly from residual indentation marks at various contact depths (ratio of contact depth to indenter radius between 0.1 and 0.9 ) and were determined as a function of contact depth. Frame compliance was found to depend on contact depth especially at small indentation depths, which is successfully explained using the concept of an extended frame boundary. Improved representative stress-strain values as well as hardness and elastic modulus were obtained over the entire contact depth.
\end{abstract}

\section{INTRODUCTION}

Instrumented indentation testing (IIT), which measures penetration load and depth continuously, is widely used to evaluate mechanical properties at microscales ${ }^{1-16}$ because it is a simple procedure that is relatively nondestructive and easy to use on small scales. In IIT, elastic modulus (a measure of resistance to elastic deformation) and hardness (a measure of resistance to plastic deformation) are generally evaluated by analyzing the indentation load-depth curve without observing the residual indentation marks. ${ }^{3}$ IIT has also been applied to evaluate flow properties, ${ }^{17-30}$ residual stress, ${ }^{31-33}$ and fracture toughness. ${ }^{34-37}$

Corrections for imperfect indenter geometry and frame compliance play a critical role in the accuracy of IIT, because the real indenter geometry is not ideal and the measured displacement is not the same as the penetration depth of indenter due to frame compliance when the instruments do not use the surface reference for depth sensor. Oliver and Pharr ${ }^{3}$ suggested a general correction method for the imperfect geometry of a sharp Berkovich indenter and frame compliance in which an area function is given by

$$
\begin{aligned}
A_{c}= & 24.5 h_{c}^{2}+C_{1} h_{c}+C_{2} h_{c}^{1 / 2}+C_{3} h_{c}^{1 / 4} \\
& +\cdots+C_{8} h_{c}^{1 / 128},
\end{aligned}
$$

\footnotetext{
a) Address all correspondence to this author.

e-mail: jyk@caltech.edu
}

DOI: $10.1557 / J M R .2009 .0358$ where $A_{c}$ is the contact area, $h_{c}$ is the contact depth, and $C_{1}$ through $C_{8}$ are constants correcting for imperfect indenter geometry that are usually determined by fitting points of contact area versus contact depth obtained for a standard sample. In the Oliver-Pharr method, the inverse of measured total stiffness $S_{\text {total }}$ is given by the sum of frame compliance $C_{\text {frame }}$ and the inverse of sample stiffness $S_{\text {sample }}$ as

$$
\frac{1}{S_{\text {total }}}=C_{\text {frame }}+\frac{1}{S_{\text {sample }}}=C_{\text {frame }}+\frac{\sqrt{\pi}}{2 \cdot E_{r} \sqrt{A_{c}}} .
$$

Here $E_{r}$ is the reduced modulus expressed by

$$
\frac{1}{E_{r}}=\frac{\left(1-v^{2}\right)}{E}+\frac{\left(1-v_{i}^{2}\right)}{E_{i}},
$$

where $E$ and $v$ are the elastic modulus and Poisson's ratio of the sample and $E_{i}$ and $v_{i}$ are the elastic modulus and Poisson's ratio of the indenter. Assuming that $C_{\text {frame }}$ and $E_{r}$ are constants regardless of contact depth, the intercept of the plot of $1 / S_{\text {total }}$ versus $A_{c}{ }^{-1 / 2}$ is determined as $C_{\text {frame }}$. The iteration should be performed until the input and evaluated frame compliances match, because contact area and frame compliance are interrelated.

Whereas corrections for indenter geometry and frame compliance for a sharp indenter are widely used in nanoindentations, ${ }^{12-14,38-40}$ the corrections for a spherical indenter have not been systematically established. Spherical indenters are highly desirable at micro- and nanoscales because they can induce various stress-strain fields depending on indentation depth. ${ }^{41}$ Evaluating tensile properties by determining representative stress-strain 
points is a good example of the use of a spherical indenter at small scales. ${ }^{17-30}$ However, spherical indenters are not frequently used at micro- and nanoscales not only because of the difficulty in manufacturing spherical indenters at this scale but also because of the lack of methods for correcting for imperfect indenter geometry and frame compliance.

In this study, we suggest a novel method to correct for imperfect indenter geometry and frame compliance for a spherical indenter at microscale. By profiling the residual indentation marks of spherical indenters at various indentation depths, effective radii calibrating the real contact area and angle are determined; these are then verified using flow properties and hardness values evaluated by different spherical indenters. A simple calibration method for indenter geometry is proposed using a reference curve for hardness versus effective strain. In addition, frame compliance is derived not as a constant but as a function of contact depth, and it is then compared with experimental results analyzed by elastic contact theory.

\section{EXPERIMENTS}

Five commonly used spherical indenters with nominal radius $250 \mu \mathrm{m}$, which are machined from tungsten carbide by a rotating diamond grinder, are prepared. A series of IITs using these indenters was performed on structural metals SKH51, SUS440, S45C, and Al6061, and on a standard hardness block of Vickers hardness 298 (Yamamoto, Japan); the testing apparatus (AIS 3000; Frontics, Seoul, Korea) had a load resolution of $5.6 \mathrm{gf}$ and a depth resolution of $0.1 \mu \mathrm{m}$. The flow properties of SKH51, SUS440, S45C, and Al6061 were evaluated by a representative stress-strain approach by 10 partial unloadings at maximum indentation depth $100 \mu \mathrm{m}$ and a loading rate of $1 \mathrm{~mm} / \mathrm{min} .{ }^{17-20}$ Flow properties of the materials were also measured in uniaxial tension tests using an Instron 5582 (Instron, Norwood, MA) at a cross-head rate of $1 \mathrm{~mm} / \mathrm{min}$. To directly measure plastic pileup in the standard-hardness block, three-dimensional (3D) profiles of the residual indentation marks at various indentation depths between 10 and $100 \mu \mathrm{m}$ were directly observed by 3D surface profiler (SIS series; SNU Precision, Seoul, Korea) with a depth resolution of $0.1 \mathrm{~nm}$. The elastic modulus and Poisson's ratio of the standard-hardness block were determined to be $203 \mathrm{GPa}$ and 0.29 , respectively, by an ultrasonic pulse-echo technique using a twochannel digital real-time oscilloscope.

\section{RESULTS AND DISCUSSION}

\section{A. Effective radius}

Figure 1 compares representative stress-strain points evaluated by three spherical indenters in IIT and stressstrain curves measured by uniaxial tension tests. The representative stress-strain points tend to overestimate the representative stress at low representative strains. We believe that all data points in IIT were measured at fully developed plastic zone regions even at the shallowest indentation depth. One general criterion for fully plastic zone in a spherical indentation is $E a_{c} / \sigma_{y} R$ greater than 50, where $a_{c}, \sigma_{y}$, and $R$ are contact radius, yield strength, and indenter radius. ${ }^{41,42}$ These values are
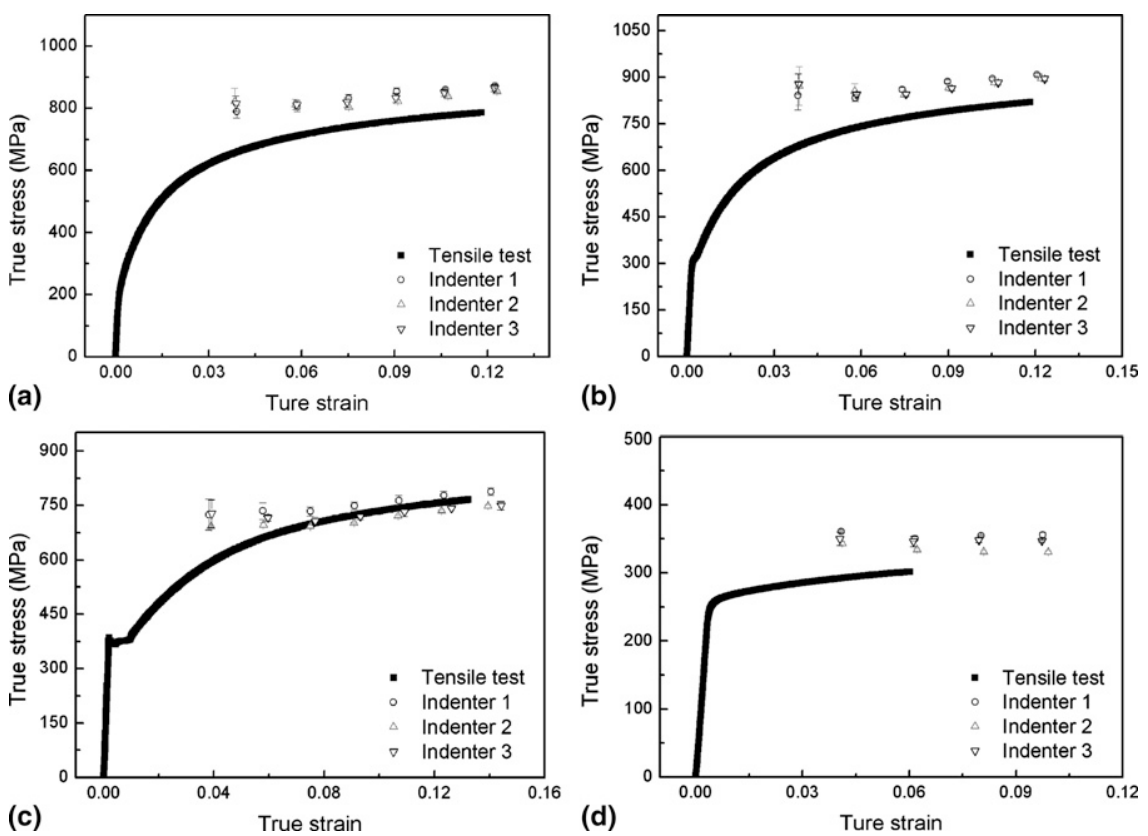

FIG. 1. Stress-strain curves and representative stress-strain points evaluated by conventional contact radius for (a) SKH51, (b) SUS440, (c) S45C, and (d) Al6061. 
172 185 for SKH51, 131 137 for STS440, 136 139 for $\mathrm{S} 45 \mathrm{C}$, and $67 \sim 68$ for Al6061, which exceed the boundary of transition regime to fully plastic region. These results indicate that the overestimation of the representative stress at low strains is not caused by pronounced elastic recovery at shallow indentation depth but is likely due to somewhat discordance between nominal indenter radius and effective local radius caused by imperfect mechanical milling of the indenter. ${ }^{43-45}$

Figure 1 also shows that the representative stressstrain points measured by different indenters do not match due to the difference in real geometries, even though they have the same nominal radius. The disagreements between the representative stress-strain points and stress-strain curves and among the representative stressstrain points evaluated by three different spherical indenter are probably caused by the imperfect indenter geometry of the indenters used here, because representative stress-strain points for the same materials evaluated by a precise spherical indenter agree well with the stressstrain curves. ${ }^{19,20}$

The contact depth was evaluated by directly measured maximum indentation depth $\left(h_{\max }\right)$, elastic deflection $\left(h_{d}\right)$, and plastic pileup $\left(h_{p}\right)$ around the indenter as

$$
h_{c}=h_{\max }-h_{d}+h_{p} \quad .
$$

Here the elastic deflection was determined by the Oliver-Pharr method ${ }^{3}$ as

$$
h_{d}=\varepsilon \frac{P_{\max }}{S},
$$

where $\varepsilon$ is the indenter geometrical constant $(0.75$ for the paraboloid of revolution), $P_{\max }$ is the maximum indentation load, and $S$ is the initial unloading stiffness. The plastic pileup can be measured experimentally by profiling the residual indentation marks after unloading.
For a spherical indenter, the contact area is given by the contact depth and the nominal indenter radius $R$ as

$$
A_{c}=\pi \cdot a_{c}^{2}=\pi \cdot\left(2 R h_{c}-h_{c}^{2}\right) .
$$

The representative stress and strain are defined by

$$
\begin{gathered}
\sigma_{r}=\frac{1}{\psi} \cdot \frac{P_{\max }}{A_{c}}, \\
\varepsilon_{r}=\frac{\alpha}{\sqrt{1-\left(a_{c} / R\right)^{2}}} \cdot \frac{a_{c}}{R},
\end{gathered}
$$

where $\psi$ is a plastic constraint factor of 3.0 and $\alpha$ is a constant of $0.14 .^{17-20}$

The effective indenter radius at a given indentation depth can differ from the nominal radius unless geometry of a spherical indenter is ideal. Figure 2 shows the contact morphology of a spherical indenter with imperfect geometry and a sample with pileup. The effective radius $\left(R_{e f f}\right)$ of an effective sphere is simply given by

$$
R_{\text {eff }}=\frac{a_{c}^{2}+h_{c}^{2}}{2 h_{c}} .
$$

Elastic recovery in the plane direction during unloading is known to be negligible, ${ }^{46}$ so the contact depth and contact area can be measured experimentally by profiling the residual indentation marks. Figure 3 shows the effective radius measured from the profiles of the residual indentation marks on the standard-hardness block generated at each indentation depth versus contact depth for three spherical indenters. The spherical indenters appear to be blunter than the nominal indenter radius at shallow indentation depths, in agreement with previous reports. ${ }^{44}$ However, as shown in Fig. 4, the representative stress-strain points analyzed using the effective radius show excellent agreement with the stress-strain

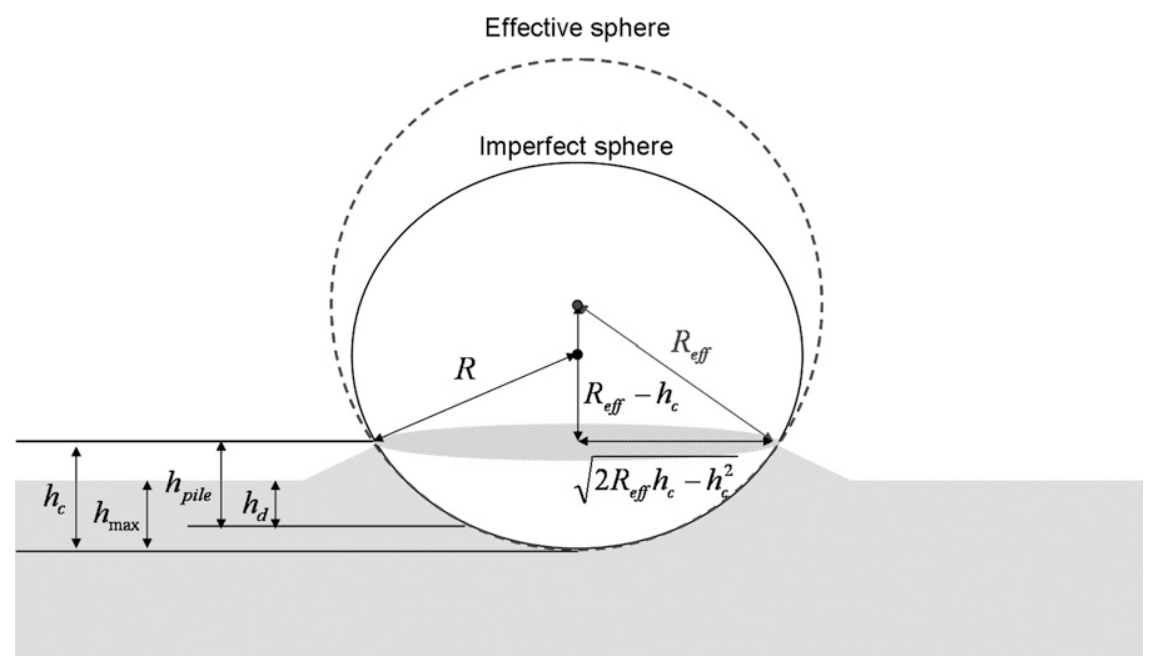

FIG. 2. Contact morphology and effective radius of imperfect spherical indenter. 
curves measured in uniaxial tension tests and with the representative stress-strain points evaluated by the different indenters. Figure 5 shows the hardness values at each indentation depth using a nominal indenter radius and the experimentally measured effective radius for the standard-hardness block. The consistency of the hardness values measured by three different spherical indenters indicates the corrections for imperfect indenter geometry using the concept of effective radius are reasonable.

\section{B. Reference curve to determine effective radius}

As shown in Fig. 5(b), the reference curve for hardness versus contact ratio $\left(a_{c} / R_{\text {eff }}\right)$ for the standard hardness block was obtained from experimentally observed

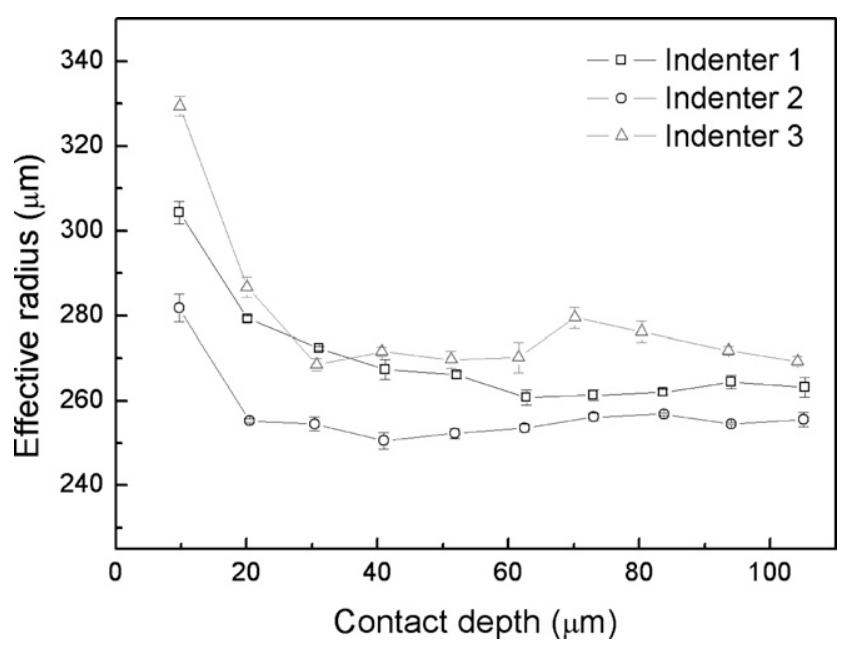

FIG. 3. Experimentally determined effective radius versus contact depth. residual indentation marks for three different spherical indenters. With this reference curve, effective radii of any spherical indenters at various indentation depths can be simply determined by the procedure in Fig. 6 with no additional observation of the residual indentation marks. The hardness and contact ratio are calculated using an arbitrary effective radius with experimentally measured indentation data at each unloading, $h_{\max }, P_{\max }$, and $S$; these are then compared with the reference curve, and the calculations are iterated until they agree. The effective radii of two new indenters (indenters 4 and 5) are evaluated using the reference curve without observing residual indentation marks, as shown in Fig. 7. Figure 8 shows the representative stress-strain points evaluated using the effective radii for indenters 4 and 5; these agree well with the stress-strain curves measured by uniaxial tension curves and the representative stressstrain points evaluated by indenter 1 .

\section{Variation in frame compliance}

Figure 9 shows elastic moduli of the standard hardness block at various indentation depths determined by the effective radii of indenters 1 through 3 using Eq. (3). Even though true contact areas were believed to be used to derive these elastic moduli, they were found to underestimate the true elastic modulus with decreasing contact depth. The results are consistent with the work of Maneiro and Rodríguez, ${ }^{47,48}$ showing an increase in elastic modulus with increasing contact depth at the nanoscale. If the measured stiffness and contact area are correct, the error in the elastic modulus is most likely caused by frame compliance, by Eqs. (2) and (3).
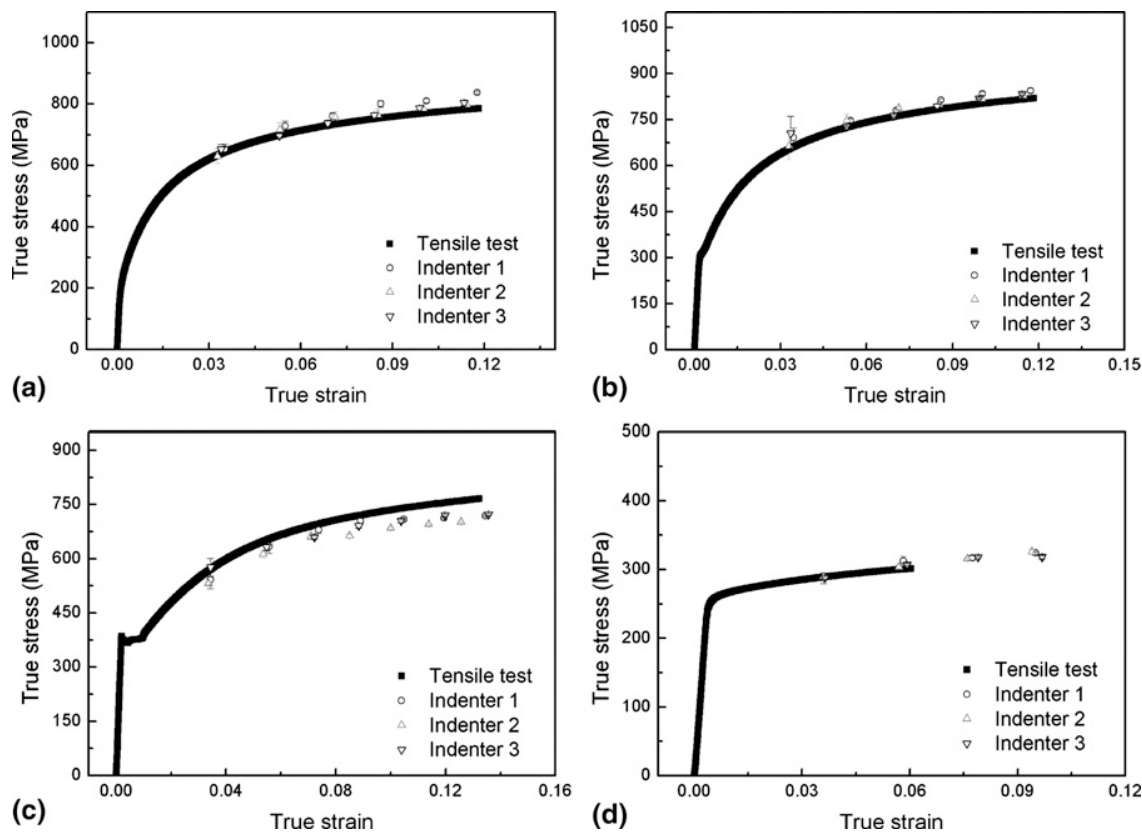

FIG. 4. Stress-strain curves and representative stress-strain points evaluated by effective radius. 


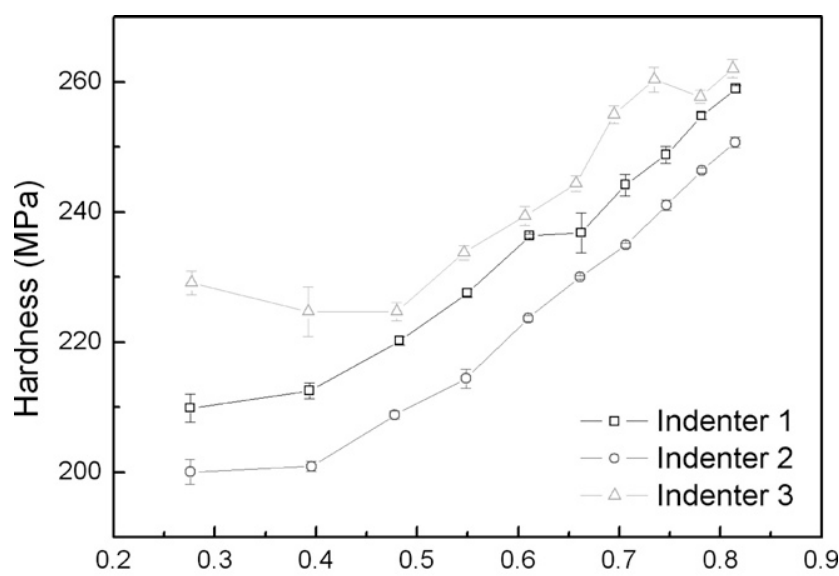

(a)

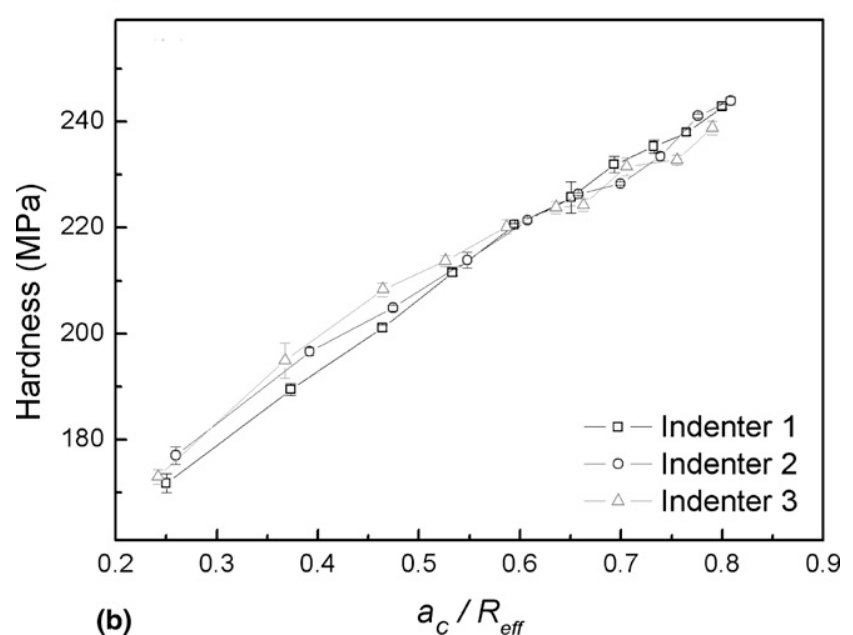

FIG. 5. Hardness versus effective strain presented with (a) nominal and (b) effective indenter radius.

Frame compliance is generally taken as a constant regardless of indentation depth by assuming that the boundary of the frame does not change. However, the contact volume corresponding to the indenter volume beneath the projected contact area induces material deformation and the remainder of the indenter transfers the load, so that the contact depth can be defined as a boundary between frame and indenter. Using this concept of frame boundary, frame compliance is given by the sum of the compliance for an indenter remainder $\left(C_{\text {indenter }}\right)$ and conventional frame compliance $\left(C_{0}\right)$ (see Fig. 10):

$$
C_{\text {frame }}=C_{\text {indenter }}+C_{0} \text {. }
$$

The compliance of a system with a constant crosssectional area $A$ and height $h^{*}$ is given by

$$
C=\frac{1}{E} \cdot \frac{h^{*}}{A},
$$

where $E$ is the elastic modulus of the system. The compliance of the indenter remainder for a spherical indenter

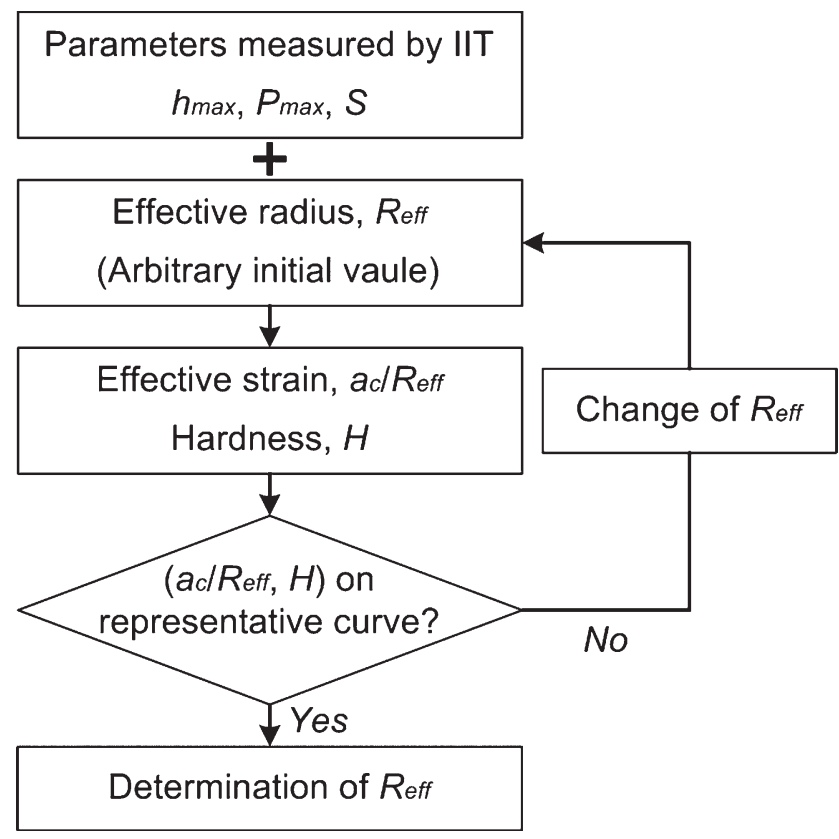

FIG. 6. Flow chart for determining effective radius with a reference curve.

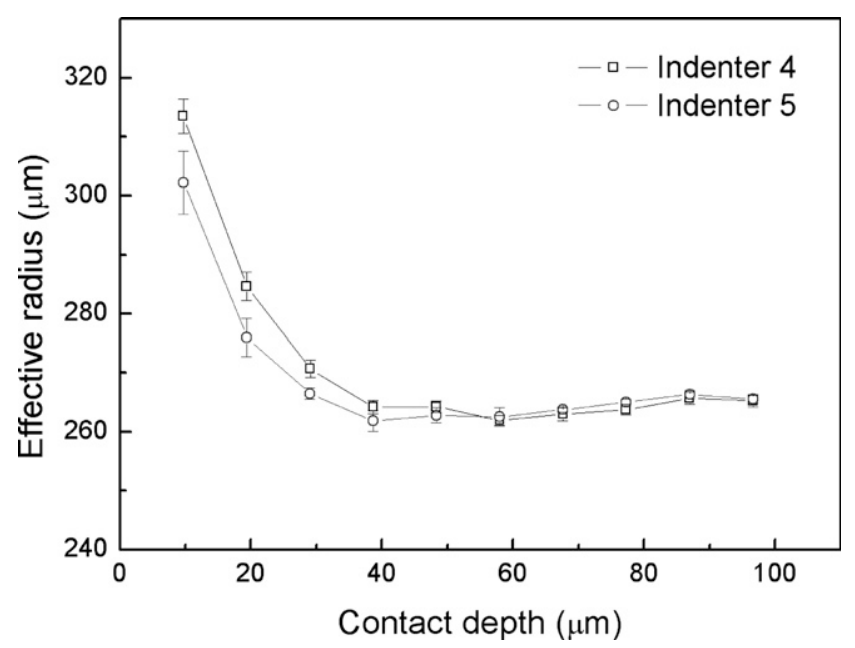

FIG. 7. Effective radius indirectly determined by reference curve versus contact depth.

is simply calculated by integration of infinite thin circular plates as

$$
\begin{aligned}
C_{\text {indenter }}= & \frac{1}{E} \cdot \frac{l-h_{c}}{\pi} \lim _{n \rightarrow \infty} \sum_{k=1}^{n} \\
& \times \frac{1}{2 R\left(h_{c}+\frac{(k-1)\left(l-h_{c}\right)}{n}\right)-\left(h_{c}+\frac{(k-1)\left(l-h_{c}\right)}{n}\right)^{2}},
\end{aligned}
$$

where $l$ is the total height of the spherical indenter and $k$ is the number of parts (see Fig. 11). $C_{\text {indenter }}$ is 

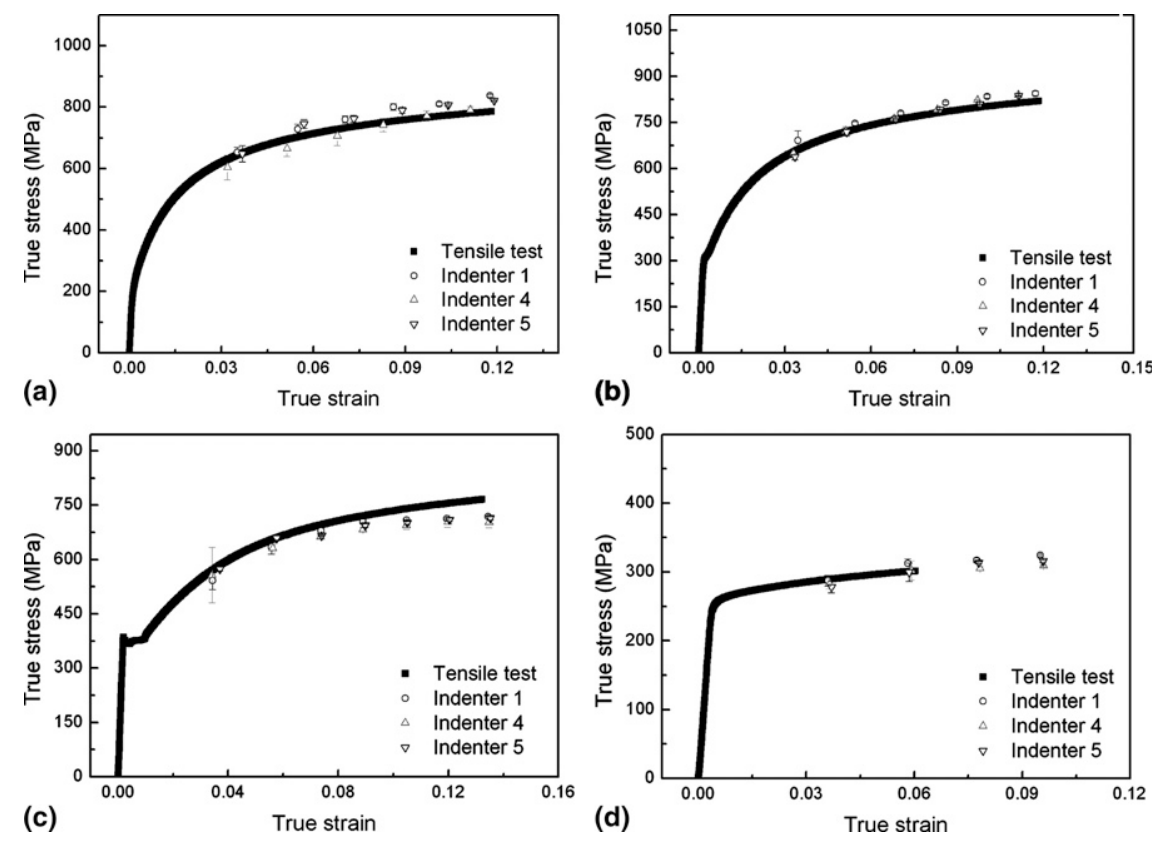

FIG. 8. Stress-strain curves and representative stress-strain points evaluated by effective radius derived with reference curve for (a) SKH51, (b) SUS440, (c) S45C, and (d) Al6061.

derived as a function of indenter geometry and contact depth as

$$
\begin{aligned}
C_{\text {indenter }}= & \frac{1}{E} \cdot \frac{l-h_{c}}{\pi} \\
& \times \int_{0}^{1} \frac{1}{2 R\left(h_{c}+\left(l-h_{c}\right) \cdot x\right)-\left(h_{c}+\left(l-h_{c}\right) \cdot x\right)^{2}} d x \\
= & \frac{1}{E} \cdot \frac{1}{\pi} \cdot \frac{1}{2 R} \cdot \ln \frac{l\left(2 R-h_{c}\right)}{h_{c}(2 R-l)}=\frac{1}{E} \cdot \frac{1}{\pi} \cdot \frac{1}{2 R} \\
& \cdot \ln \frac{l}{(2 R-l)}\left(\frac{2 R}{h_{c}}-1\right) .
\end{aligned}
$$

Figure 12 compares theoretical frame compliance [Eq. (13)] and experimental results inversely calculated by Eq. (2) using the elastic modulus measured by the ultrasonic method, where $C_{0}$ was set at an experimental value, $0.65 \mu \mathrm{m} / \mathrm{kgf}$. At shallow indentation depths, the frame compliance was found to be strongly dependent on contact depth. Frame compliance decreases as a logarithmic function of the inverse of contact depth because the increase in contact area decreases steeply with increasing depth in spherical geometry. Thus, the initial step shows large compliance variation and had to be calibrated with the functional compliance values. Even though the frame compliance of the nonindenter part is generally large, the indenter compliance itself is significant at shallow indentation depths. Figure 13 shows the elastic moduli of four different materials after calibrating the compliance as a function of indentation depths, which are consistent over the whole indentation depths.

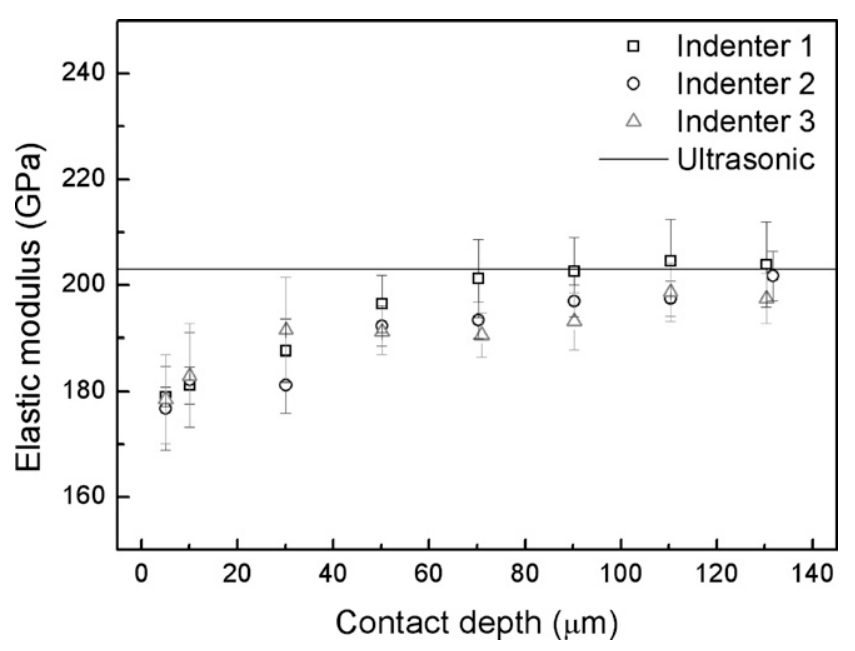

FIG. 9. Elastic modulus of standard-hardness block measured by ultrasonic method and by IIT using conventional correction of frame compliance.

\section{Continuous calibration of frame compliance and effective radius}

As mentioned above, frame compliance is given as a function of contact depth, which depends on the calibration of the frame compliance. For this reason, the following iteration is suggested to determine the exact indentation depth:

$$
h^{n}=h^{0}-f\left(h_{c}^{n-1}\right) \cdot P^{0}
$$

where $h^{0}$ and $P^{0}$ are the measured indentation depth and load, $h^{n}$ is the $n$th calibrated contact depth, $h_{c}^{n-1}$ is the 

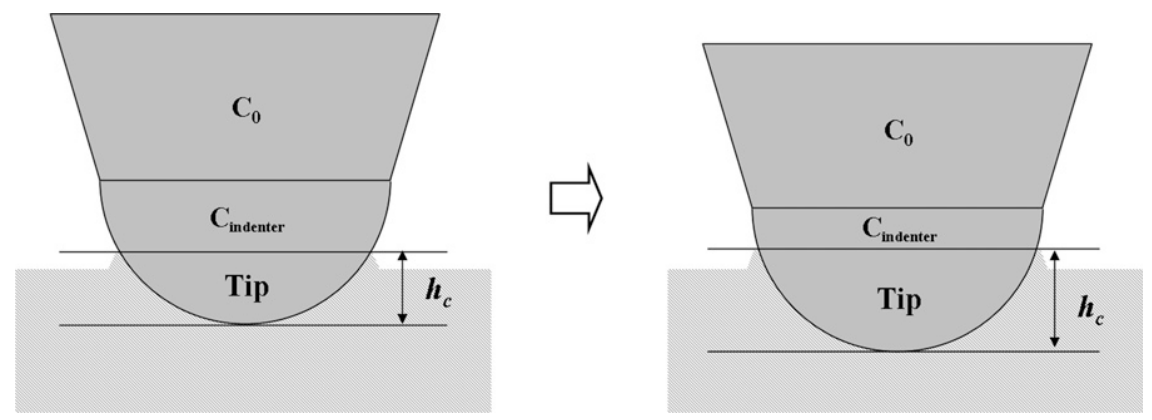

FIG. 10. Definition of boundary between tip and frame.

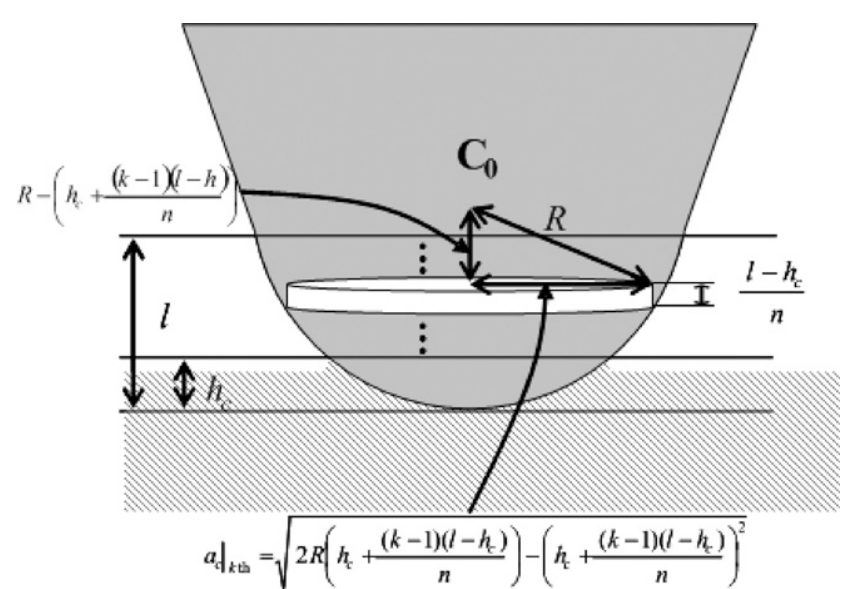

FIG. 11. Schematic for calculation of frame compliance for spherical indenter.

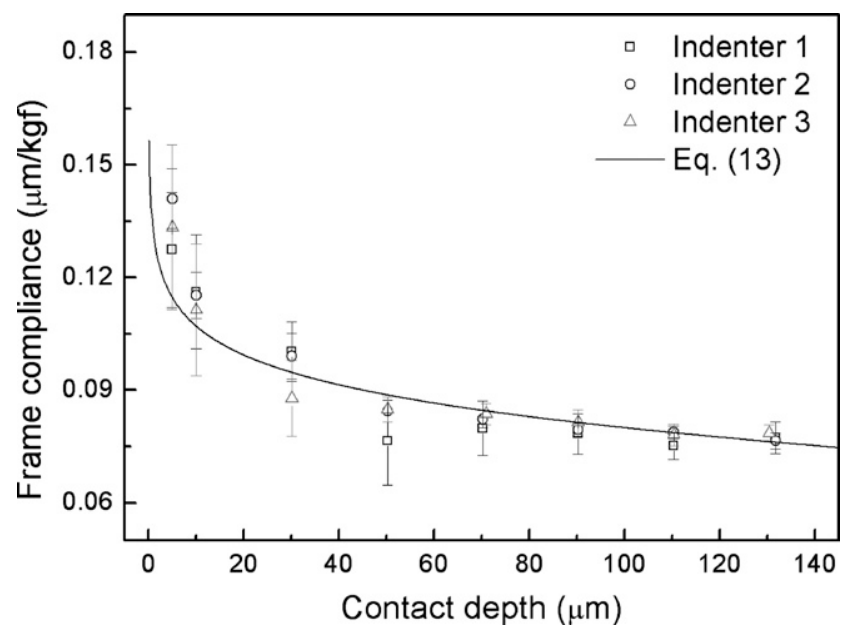

FIG. 12. Expected and measured frame compliances as a function of contact depth.

contact depth calculated from the $(n-1)$ th calibrated contact depth, and $f\left(h_{c}^{n-1}\right) \cdot P^{0}$ is the frame deformation. The convergent $h^{n}$ is the true contact depth, which takes into account the calibrations of frame compliance and effective radius.

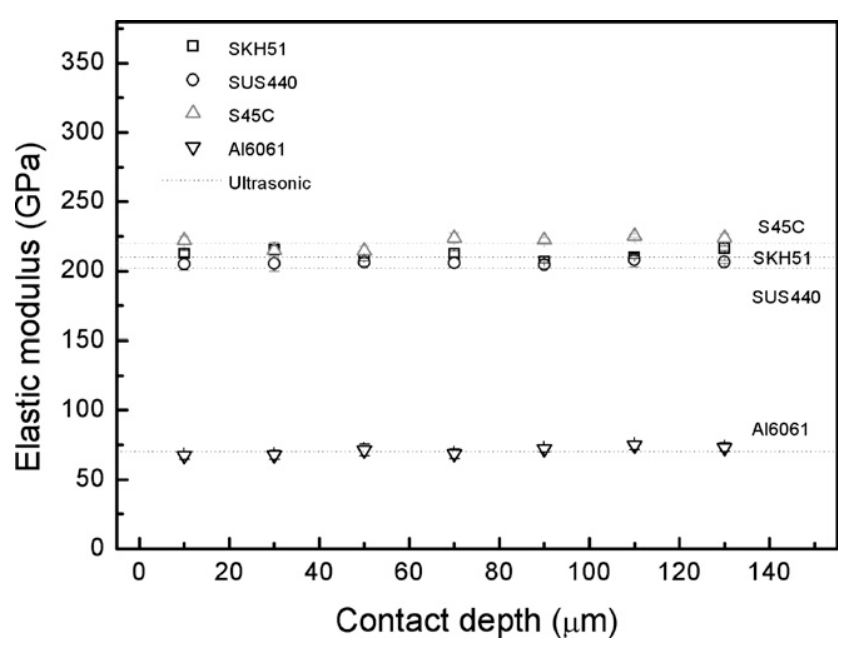

FIG. 13. Elastic moduli at various indentation depths after compliance calibration.

\section{CONCLUSIONS}

We proposed methods to correct for imperfect indenter geometry and frame compliance in IIT using a spherical indenter at microscale. The effective radii of the three spherical indenters with a nominal radius of $250 \mu \mathrm{m}$ were determined experimentally at each partial unloading indentation depth. When calculating hardness values and the representative stress-strain points at each partial unloading contact depth using the effective radii, those measured by three different indenters were found to agree with one another, and the representative stressstrain points matched the stress-strain curves over the entire strain region. Effect radii of two other indenters (indenter nos. 4 and 5) were determined only by analysis of load-displacement curves using the reference curve for the relationship between hardness and effective strain experimentally obtained by three indenters (indenters 1-3). The representative stress-strain points evaluated by the effective radii of indenters 4 and 5 also agreed with those from the experimentally evaluated effective and stress-strain curves.

We introduced a novel frame compliance concept to correct depth-dependent measured elastic moduli despite 
imperfect indenter geometry, as corrected by the effective radius. We showed that the compliance of a spherical indenter is proportional to the logarithms of the inverse of the contact depth [Eq. (13)], so that variation in frame compliance at shallow indentation depths has a strong influence on the elastic modulus. Because the frame compliance is a function of contact depth and also affects the contact depth, an iterative calculation was suggested to determine the correct frame compliance and effective radius. These results imply that the representative stress-strain points as well as hardness and elastic modulus over the entire contact depth can be evaluated by IIT using a spherical indenter by correcting for imperfect indenter geometry and frame compliance.

\section{ACKNOWLEDGMENTS}

This research was supported in part by the Seoul R\&BD Program (Grant No. TR080564) of the Seoul Development Institute, Korea, and in part by the Center for Nanoscale Mechatronics and Manufacturing under The 21st Century Frontier R\&D Program (Grant No. M102KN010006-08K1401-00621) of the Ministry of Education, Science and Technology, Korea.

\section{REFERENCES}

1. S.I. Bulychev, V.P. Alekhin, M.K. Shorshorov, A.P. Ternovskii, and G.D. Shnyrev: Determining Young's modulus from the indentor penetration diagram. Zavod. Lab. 41, 1137 (1975).

2. M.F. Doerner and W.D. Nix: A method for interpreting the data from depth-sensing indentation instruments. J.Mater. Res. 1, 601 (1986).

3. W.C. Oliver and G.M. Pharr: An improved technique for determining hardness and elastic-modulus using load and displacement sensing indentation experiments. J.Mater. Res. 7,1564 (1992).

4. A. Gouldstone, N. Chollacoop, M. Dao, J. Li, A.M. Minor, and Y.L. Shen: Indentation across size scales and disciplines: Recent developments in experimentation and modeling. Acta Mater. $\mathbf{5 5}$ 4015 (2007).

5. A.C. Fischer-Cripps: A review of analysis methods for sub-micron indentation testing. Vacuum 58, 569 (2000).

6. N.K. Mukhopadhyay and P. Paufler: Micro- and nanoindentation techniques for mechanical characterisation of materials. Int. Mater.Rev. 51, 209 (2006).

7. J.S. Field and M.V. Swain: Determining the mechanicalproperties of small volumes of material from submicrometer spherical indentations. J.Mater. Res. 10.101 (1995).

8. C.A. Schuh: Nanoindentation studies of materials. Mater. Todav 9,32(2006).

9. D. Tabor: Hardness of Metals (Clarendon Press, Oxford, 1951).

10. A. Bolshakov and G.M. Pharr: Influences of pileup on the measurement of mechanical properties by load and depth-sensing indentation techniques. J. Mater. Res. 13, 1049 (1998).

11. A.C. Fischer-Cripps: Nanoindentation (Springer, New York, 2002).

12. W.C. Oliver and G.M. Pharr: Measurement of hardness and elastic modulus by instrumented indentation: Advances in understanding and refinements to methodology. J. Mater. Res. 19, 3 (2004).

13. Y.T. Cheng and C.M. Cheng: Scaling, dimensional analysis, and indentation measurements. Mater. Sci. Eng., R 44, 91 (2004).
14. J.Y. Kim, B.W. Lee, D.T. Read, and D. Kwon: Influence of tip bluntness on the size-dependent nanoindentation hardness. $\underline{S c r}$. Mater. 52, 353 (2005).

15. J.Y. Kim, S.K. Kang, J.R. Greer, and D. Kwon: Evaluating plastic flow properties by characterizing indentation size effect using a sharp indenter. Acta Mater. 56, 3338 (2008).

16. J.Y. Kim, S.K. Kang, J.J. Lee, J.I. Jang, Y.H. Lee, and D. Kwon: Influence of surface-roughness on indentation size effect. Acta Mater. 55, 3555 (2007).

17. J.H. Ahn and D. Kwon: Derivation of plastic stress-strain relationship from ball indentations: Examination of strain definition and pileup effect. J.Mater. Res. 16, 3170 (2001).

18. S.H. Kim, B.W. Lee, Y. Choi, and D. Kwon: Quantitative determination of contact depth during spherical indentation of metallic materials: A FEM study. Mater. Sci. Eng., A 415, 59 (2006).

19. J.Y. Kim, K.W. Lee, J.S. Lee, and D. Kwon: Determination of tensile properties by instrumented indentation technique: Representative stress and strain approach. Surf. Coat. Technol. 201. $4278(2006)$

20. E.C. Jeon, J.Y. Kim, M.K. Baik, S.H. Kim, J.S. Park, and D. Kwon: Optimum definition of true strain beneath a spherical indenter for deriving indentation flow curves. Mater. Sci. Eng. A 419.196(2006).

21. B. Taljat, T. Zacharia, and F. Kosel: New analytical procedure to determine stress-strain curve from spherical indentation data. Int. J. Solids Struct. 35, 4411 (1998)

22. M. Dao, N. Chollacoop, K.J. Van Vliet, T.A. Venkatesh, and S. Suresh: Computational modeling of the forward and reverse problems in instrumented sharp indentation. Acta Mater. 49, 3899 (2001).

23. N. Chollacoop, M. Dao, and S. Suresh: Depth-sensing instrumented indentation with dual sharp indenters. Acta Mater. 51. 3713 (2003).

24. E.G. Herbert, G.M. Pharr, W.C. Oliver, B.N. Lucas, and J.L. Hay: On the measurement of stress-strain curves by spherical indentation. Thin Solid Films 398-399, 331 (2001).

25. S. Jayaraman, G.T. Hahn, W.C. Oliver, C.A. Rubin, and P.C. Bastias: Determination of monotonic stress-strain curve of hard materials from ultra-low-load indentation tests. Int. J. Solids Struct. 35, 365 (1998).

26. Y.T. Cheng and C.M. Cheng: Scaling relationships in conical indentation of elastic perfectly plastic solids. Int. J. Solids Struct. 36, 1231 (1999).

27. A.E. Giannakopoulos and S. Suresh: Theory of indentation of piezoelectric materials. Scr. Mater. 40, 1191 (1999).

28. T.A. Venkatesh, K.J. Van Vliet, A.E. Giannakopoulos, and S. Suresh: Determination of elasto-plastic properties by instrumented sharp indentation: Guidelines for property extraction. Scr. Mater. 42, 833 (2000).

29. J.L. Bucaille, S. Stauss, E. Felder, and J. Michler: Determination of plastic properties of metals by instrumented indentation using different sharp indenters. Acta Mater. 51, 1663 (2003).

30. K.D. Bouzakis and N. Michailidis: Coating elastic-plastic properties determined by means of nanoindentations and FEM-supported evaluation algorithms. Thin Solid Films 469-470, 227 (2004).

31. S. Suresh and A.E. Giannakopoulos: A new method for estimating residual stresses by instrumented sharp indentation. Acta Mater. 465, 755 (1998).

32. Y.H. Lee and D. Kwon: Estimation of biaxial surface stress by instrumented indentation with sharp indenters. Acta Mater. $\mathbf{5 2}$ 1555 (2004).

33. Y.H. Lee, J.Y. Kim, J.S. Lee, K.H. Kim, J.Y. Koo, and D. Kwon: Using the instrumented indentation technique for stress characterization of friction stir-welded API X80 steel. Philos. Mag. 86. $\underline{5497(2006)}$. 
34. J.S. Lee, J.I. Jang, B.W. Lee, Y. Choi, S.G. Lee, and D. Kwon: An instrumented indentation technique for estimating fracture toughness of ductile materials: A critical indentation energy model based on continuum damage mechanics. Acta Mater. 54, 1101 (2006).

35. B.R. Lawn and E.R. Fuller: Equilibrium penny-like cracks in indentation fracture. J. Mater. Sci. 10, 2016 (1975).

36. B.R. Lawn, A.G. Evans, and D.B. Marshall: Effect of residual contact stresses on mirror-flaw-size relations. J. Am. Ceram. SoC. 63, $574(1980)$.

37. T.S. Byun, J.W. Kim, and J.H. Hong: A theoretical model for determination of fracture toughness of reactor pressure-vessel steels in the transition region from automated ball indentation test. J. Nucl. Mater. 252, 187 (1998).

38. J.Y. Kim, S.H. Kim, J.S. Lee, K.W. Lee, and D. Kwon: Mechanical characterization of nano-structured materials using nanoindentation. Met. Mater. Int. 12, 219 (2006).

39. Y.G. Wei, X.Z. Wang, and M.H. Zhao: Size effect measurement and characterization in nanoindentation test. J.Mater. Res. 19. 208 (2004).

40. J.G. Swadener, E.P. George, and G.M. Pharr: The correlation of the indentation size effect measured with indenters of various shapes. J. Mech. Phys. Solids 50, 681 (2002).
41. K.L. Johnson: Contact Mechanics (Cambridge University Press, Cambridge, 1985).

42. Y.J. Park and G.M. Pharr: Nanoindentation with spherical indenters: Finite element studies of deformation in the elastic-plastic transition regime. Thin Solid Films 447-448, 246 (2004).

43. W.W. Gerberich, J.C. Nelson, E.T. Lilleodden, P. Anderson, and J.T. Wyrobek: Indentation induced dislocation nucleation: The initial yield point. Acta Mater. 44, 3585 (1996).

44. Y.L. Chiu and A.H.W. Ngan: A TEM investigation on indentation plastic zones in $\mathrm{Ni}_{3} \mathrm{Al}(\mathrm{Cr}, \mathrm{B})$ single crystals. Acta Mater. 50. 1599 (2002).

45. H. Bei, E.P. George, J.L. Hay, and G.M. Pharr: Influence of indenter tip geometry on elastic deformation during nanoindentation. Phvs. Rev. Lett. 95, 045501 (2005).

46. J. Alcalà, A.C. Barone, and M. Anglada: The influence of plastic hardening on surface deformation modes around Vickers and spherical indents. Acta Mater. 48, 3451 (2000).

47. M.A.G. Maneiro and J. Rodríguez: A new consideration on spherical depth-sensing indentation. J. Mater. Lett. 62, 69 (2008).

48. J. Rodríguez and M.A.G. Maneiro: A procedure to prevent pile up effects on the analysis of spherical indentation data in elasticplastic materials. Mech. Mater. 39, 987 (2007). 